\title{
Lamb and Love wave propagation in an infinite micropolar elastic plate
}

\author{
E. Boschn (*) \\ Receivert on February 2nil, 1973
}

\begin{abstract}
Suy Hary, - This paper is conecrned with monochromatic wave propagation in an infinite houtogeneous nieropolar dastic plate bounded by two parallel free planes. Two kinuls of propagation are discnssed: Lamb and love waves. We find that a displacement field $\left(u_{1}, u_{\mathrm{s}}, 0\right)$ and a microrotation ficld $\left(0,0, p_{3}\right)$ leals to Lamb's waves, while a displacement field (6), $\left.0, n_{3}\right)$ and a microrntation feld $\left(\varphi_{1}, \varphi_{2}, 0\right)$ leads to luve s waves.
\end{abstract}

Russuxto. - In questo lavorn si tratta la propagazione di onde monocromatiche in nn piatto elastico, micropolare, omogeneo ed infinito, limitato da the piani paralleli e liberi. Vengono tisenssi dne tipi di propagazione, quello di lamh o quello di Love. Si hova che il campo di spostamenti $\left(u_{1}, u_{3}, 0\right)$ ed il empo di microrotazioni $\left(0,0, F_{3}\right)$ porta ad onse di Lamb, mentre un campo di spostamenti $\left(0,0, u_{3}\right)$ ed un campo ili micro. rotazioni $\left(\varphi_{1}, \varphi_{2}, 0\right)$ poria ad onde di Jove.

\section{INTRODUCTION}

Oseillations of an elastic plate, with stress-free surfaces, have been investigated by Rayleigh (19), Jamb (11) and others, and more recently by Prescott (12), Gogolatze $\left({ }^{9}\right)$, Sato $\left({ }^{1-1}\right)$ and Fing, Jirkletzky inul Press (1).

In this paper we want to real with the same problem in the framework of the theory of micropolar elisticity.

(*) Istituto di Fisica, Lniversità di Bologna.

bipartimento di scienze della Terra, Lniversita di Aneona (Italy). 
The linest theory of micropolar elasticity has been introduced by Eringen (3). Jesan (11) has derived the fundamental equations using invariance couditions under superposed rigid boly motions.

Hicropolat elasticity may give interesting results when applied to geophysical problems. We have ahendy applied it to derivo an explicit expression of the body force and the body comple equivalents for seismic dislocations $(1,2)$.

B.ISIC EQUTTIOXS

Throughout this paper wo employ the usual indicial notations. All regularity hypotheses on the enonsidered funetions will be omitted.

We consider a rectangular Gartesian framo $0 x_{k}(k-1,2,3)$. The basic aquations in the linear theory of lomogeneons and anisotropie elastic solints are $\left({ }^{10}\right)$ :

- the kinematic relations:

$$
\begin{aligned}
& e_{i j}=u_{j, t}-\varepsilon_{i j k} p_{k} \\
& \varkappa_{i j}=\varphi_{j, i}
\end{aligned}
$$

- the equations of motion:

$$
\begin{aligned}
& t_{f i, s}+F_{t}=\varrho \ddot{u}_{i} \\
& \left.m_{s i, f}+\varepsilon_{i s i} t_{j k}+M_{i}=I_{i s} \ddot{\varphi}\right\}
\end{aligned}
$$

- the constitutive laws:

$$
\begin{aligned}
& t_{t\}}=A_{t j k t} e_{k t}+B_{t j k t} \varkappa_{k t} \\
& m_{l\}}=B_{k l i j} e_{k i}+C_{t j k t} \varkappa_{k l}
\end{aligned}
$$

In the above equations wo have used the following notations: $u_{i}$, the eomponents of the displacement vector; $\varphi_{t}$, the eomponents of the microrotation vector; $e_{i j}$ and $\varkappa_{t}$, the kinematic oharacteristios of the strain; $t_{f l}$, the components of the stress tensor; $m_{s i}$, the components of the eomple stress tensor; $F_{i}$, the components of the borly force; $H_{i}$, the components of the body comple; $\varrho$, the mass density; $A_{i j k l}$, 
$B_{i j k}, C_{t j k}, I_{i j}$, the characteristic constants of the material; $\varepsilon_{i j k}$, the aiternating tensor; a commi denotes partial derivation witlı respeet to space variables, and a superposed dot partial derivation with respect to the time $t$. Furthermore, we have:

$$
\begin{aligned}
& A_{t j k t}=A_{k i t} \\
& C_{t j k t}=C_{k i t} \\
& I_{t j}=I_{j t}
\end{aligned}
$$

If the body is lomogeneons, isotropic and centrosymmetric, we lave:

$$
\begin{aligned}
& A_{i j k l}=\lambda \delta_{t j} \delta_{k i}+(\mu-x) \delta_{t k} \delta_{j t}+\mu \delta_{t i} \delta_{t k} \\
& B_{i j k t}=0 \\
& C_{t j k i}=a \delta_{t}, \delta_{k t}+\gamma \delta_{i k} \delta_{j t}+\beta \delta_{u} \delta_{j k}
\end{aligned}
$$

and equations [3] are altered to:

$$
\begin{aligned}
& t_{i j}=\lambda e_{k k} \delta_{i j}+(\mu+x) e_{i j}+\mu e_{j i} \\
& m_{i j}=\alpha \varkappa_{k k} \delta_{i s}+\gamma \varkappa_{t s}+\beta \varkappa_{j i}
\end{aligned}
$$

where $\lambda, \mu, x, \alpha, \gamma$ and $\beta$ are material constants satisfying the following inequalities:

$$
\begin{aligned}
& 3 \lambda+2 \mu+\varkappa \geqslant 0 \\
& 2 \mu+x \geqslant 0 \\
& x \geqslant 0 \\
& 3 \alpha+\beta+\gamma \geqslant 0 \\
& -\gamma \leqslant \beta \leqslant \gamma \\
& \gamma \geqslant 0
\end{aligned}
$$

which are the necessary and sufficient conditions for the internal energy to be non-negative. Furthermore we can also write:

$$
I_{i}=I \delta_{i j}
$$

where $I$ is another material constant. 
If equations [5] ant [7] are substituted into equations [1], we get:

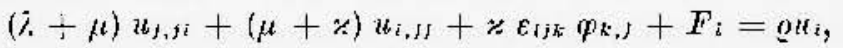

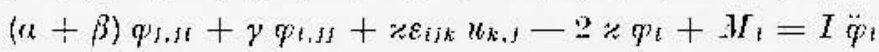

let us now specialize our anlalysis to the case in which:

$$
\begin{aligned}
& F_{i}=M_{t}=-=0 \\
& u_{t}=u_{i}\left(x_{1}, x_{0}, t\right): \phi_{i}=\phi_{t}\left(x_{1}, x_{2}, t\right)
\end{aligned}
$$

Fquations [8] leaul lo:

$$
\begin{aligned}
& (\mu+x) V-u_{1}+(\lambda+\mu) c_{, 1} \dashv-z q_{3,2}-0 u_{1} \\
& (\mu+\varkappa) V-u_{2}+(\bar{\lambda}+\mu) c_{+2}-\varkappa q_{n, 1}=\varrho u_{2}
\end{aligned}
$$

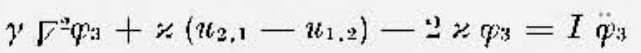

$$
\begin{aligned}
& \gamma V^{2} \phi_{1}+(a+\beta) \Theta,_{1}-2 * \psi_{1}+* u u_{3,2}=I \ddot{p}_{1} \\
& \gamma \nabla^{\prime \prime} \phi_{2} \div(\alpha+\beta) \Theta_{, 2}-2 * \phi_{2}-x \psi_{3,1}=I \ddot{p}_{2} \\
& (\mu+*) \nabla \cdot u_{3}+*\left(\varphi_{2,1}-\varphi_{1,2}\right)=\varrho u_{3}
\end{aligned}
$$

where we have introulucel the following notations:

$$
\begin{aligned}
& e=u_{1,1}+u_{2,2} \\
& \Theta=\psi_{1,1}+\varphi_{2,2} \\
& V^{2}=\partial^{2} / \partial x_{1}^{2}+\partial^{2} / \partial x_{2}{ }^{2}
\end{aligned}
$$

The two systems of equations [9.a] and [9.b] are independent. Tle spstem [9.a] rlescribes the risplacement field $\left(u_{1}, u_{2}, 0\right)$ and the microlotation liclil $\left(0,0, \phi_{3}\right)$. The spstem [9.b] describes the displucement fielrl $\left(0,0, u_{3}\right)$ and the microrotation tield $\left(q_{1}, \phi_{2}, 0\right)$. Our purpose is to slow that the system [9.a] leads to waves of Inmb kind, while the system [9.b] leacis to waves of Love kind.

\section{LAMB WAVES.}

The components of the stress and couple stress tensor determined by the displacement ficli $\left(u_{1}, u_{2}, 0\right)$ and by the microrotation fielol $\left(0,0, \phi_{3}\right)$ ate: 


$$
\begin{aligned}
& t_{11}=(2 \mu+\varkappa) u_{1,2}+\lambda e \\
& t_{22}=(2 \mu+\varkappa) u_{2,2}+\lambda e \\
& t_{33}=\lambda e \\
& t_{12}=\mu\left(u_{2,1}+u_{1,2}\right)+\% u_{2,1}-* q_{3} \\
& t_{21}=\mu\left(u_{1,2}+u_{2,1}\right)+\% u_{1,2}+\cdots q_{3} \\
& t_{13}=t_{31}-t_{23}=t_{32}=0 \\
& m_{13}=\gamma \varphi_{3,1} \\
& m_{31}=\beta \varphi_{3,1} \\
& m_{23}=\gamma q_{3,2} \\
& m_{32}=\beta \varphi_{3,2} \\
& m_{11}=m_{22}=m_{33}=m_{12}=m_{21}=0
\end{aligned}
$$

Let us now assume that a monochromatic wave propagates, along the $x_{2}$ - diection, in an infinite miaropolar elastic plate. Iet $2 H$ be the thickness of the considered plate. Horeover we assume that the following conditions:

$$
t_{11}=t_{12}=m_{13}=0, \text { at } x_{1}=\doteqdot H
$$

should be satisfiel. In other words, the surfices of the plate are supposerl free of stresses and couple strosses.

Equations [9.a] are satisfied by:

$$
\begin{aligned}
& u_{1}=\phi,_{1}-\psi_{, 2} \\
& u_{2}=\phi,_{2}+\psi_{, 1}^{\prime}
\end{aligned}
$$

providel

$$
\left.\begin{array}{l}
(\lambda+2 \mu+\varkappa) \nabla^{2} \phi-\varrho \ddot{\phi}=0 \\
(\mu+\approx) V^{2} \psi-\varrho \psi-\psi \psi_{33}=0 \\
{\left[\gamma \nabla^{2}-2 x-I \partial^{2} / \partial t^{2}\right] \phi_{3}+\nabla^{2} \psi=0}
\end{array}\right\}
$$

The first equation [12] deseribes the propagation of longitudinal displacement waves with velocity:

$$
v_{1}^{2}=\frac{\lambda+2 \mu+\varkappa}{\varrho}
$$

The last two equations [12] can be reduced to the following form: $\left\{\left[\gamma V^{2}-2 *-I \partial^{2} / \partial t^{2}\right]\left[(\mu+*) V^{2}-\varrho \partial^{2} / \partial t^{2}\right]+*^{2} V^{2}\right\} \psi^{\prime}=0$
$\left\{\left[\gamma V^{2}-2 *-I \partial^{2} / \partial t^{2}\right]\left[(\mu+x) V^{2}-\varrho \partial^{2} / \partial t^{2}\right] \div *^{2} V^{2}\right\} \psi^{3}=0$ 
Let us assume solutions of the fornt:

$$
\begin{aligned}
& \Phi\left(x_{1}, x_{2}, t\right)=\Phi^{*}\left(x_{1}\right) e^{i\left(l k x_{2} \ldots \omega t\right)} \\
& \Psi^{\prime}\left(x_{1}, x_{2}, t\right)=\Psi^{\prime *}\left(x_{1}\right) e^{i\left(k x_{2}-\omega l\right)} \\
& \varphi_{3}\left(x_{1}, x_{2}, t\right)=\varphi_{3}^{* *}\left(x_{1}\right) e^{i\left(k x_{2}-\omega t\right)}
\end{aligned}
$$

The first equation [12] and equations [14] become:

$$
\begin{aligned}
& \Phi^{*}, 11-\left(k^{2}-\frac{\omega^{2}}{v_{1}^{2}}\right) \Phi^{*}=-0 \\
& \left\{\left(\frac{d^{2}}{d x_{1}^{2}}-k^{2}+a^{2}\right)\left(\frac{d^{2}}{d x_{1}^{2}}-k^{2}+d^{2}-b^{2}\right)+\sigma^{2}\left(\frac{d^{2}}{d x_{1}^{2}}-k^{2}\right)\right\} y^{* *}=0 \\
& \left\{\left(\frac{d^{2}}{d x_{1}^{2}}-k^{2}+a^{2}\right)\left(\frac{d^{2}}{d x_{1}^{2}}-k^{2}+d^{2}-b^{2}\right)+\sigma^{2}\left(\frac{d^{2}}{d x_{1}^{2}}-k^{2}\right)\right\} p_{3}^{*}=0,
\end{aligned}
$$

where the following notations have been introdnced:

$$
\begin{aligned}
& a^{2}=\omega^{2} /\left(c_{2}{ }^{2}+c_{3}{ }^{2}\right) \\
& d^{2}=\omega^{2} / c_{4}{ }^{2} \\
& b^{2}=2 x / \gamma \\
& \sigma^{2}=x^{2} /[\gamma(\mu+*)] \\
& c_{2}^{2}=\mu / \varrho \\
& c_{3}^{2}=x / \varrho \\
& c_{4}^{2}=\gamma / I
\end{aligned}
$$

Equations [17] describe the modified transverse waves. We search solutions of equations [16] and [17] of the form:

$$
\begin{aligned}
& \Psi^{*}=A \sinh _{1}\left(\eta x_{1}\right)+B \cosh \left(\eta x_{1}\right) \\
& \Psi^{*}=C \sinh \left(k_{1} x_{1}\right)+D \cosh \left(k_{1} x_{1}\right)+F \sinh \left(k_{2} x_{1}\right)+F \cosh \left(k_{2} x_{1}\right) \\
& \varphi_{3}^{*}=G \sinh \left(k_{1} x_{1}\right)+L \cosh \left(k_{1} x_{1}\right)+I \sinh \left(k_{2} x_{1}\right)+Q \cosh \left(k_{2} x_{1}\right)
\end{aligned}
$$


wleres.

$$
\begin{aligned}
& k_{1,2^{2}}=k^{2}+\frac{1}{2}\left\{b^{2}-a^{2}-\sigma^{2}-d^{2} \pm\left(\left\{a^{2}+\sigma^{2}+d^{2}-b^{2}\right\}-\right.\right. \\
& \left.\left.\left.-4 a^{2}\left(d^{2}-b^{2}\right)\right)\right]^{1 / 2}\right\} \\
& \eta=\left(k^{2}-\frac{\omega^{2}}{v_{12}}\right)
\end{aligned}
$$

Let us now syecialize our study to the ense of symmetric vibrations. Then the component $u_{3}$ of the displacement vector, the components $t_{11}$ and $t_{22}$ of the stress tensor and the comjonent $m_{13}$ of the coujule stress tensor must be symmetric with respect to the plane $x_{1}=0$. This lades to:

$$
A=D=H^{\top}=L=Q=0
$$

and the expressions [19] are altered to:

$$
\left.\begin{array}{l}
\Phi^{*}=B \cosh \left(\eta x_{1}\right) \\
\Psi^{*}=C \sinh \left(k_{1} x_{1}\right)+E \sinh \left(k_{2} x_{1}\right) \\
\varphi_{3}^{*}=G \sinh \left(k_{1} x_{1}\right)+P \sinh \left(k_{2} x_{1}\right)
\end{array}\right\}
$$

Furthermore introducing these expressions into equations [12], we get:

$$
\begin{aligned}
& G=\tau_{1} C \\
& P=\tau_{2} E
\end{aligned}
$$

where

$$
\tau_{n}=\frac{\mu+\varkappa}{*}\left(a^{2}+\hbar^{2}-k_{n}^{2}\right), n=1,2
$$

Therefore $\varphi_{3}{ }^{*}$ can be witten as:

$$
\varphi_{3}^{*}=\tau_{1} C \sinh \left(k_{1} x_{1}\right)+\tau_{2} E \operatorname{sinl}\left(k_{2} x_{1}\right) .
$$

The boundary conditions [11] are expressed as:

$B\left[\eta^{2}(2 \mu \div \lambda+\psi)-\lambda k^{2}\right] \cosh (\eta H)-C i k_{1}(2 \mu \div *) \cosh \left(k_{1} H\right)$ $-E i k k_{2}(2 \mu+x) \cosh \left(k_{2} H\right)=0$,

$B i k \eta(2 \mu-x) \sinh (\eta H)+O \sigma_{1} \sinh \left(k_{1} H\right)+E \sigma_{2} \sinh \left(k_{2} H\right)=0$, $C k_{1} \tau_{1} \cosh \left(k_{1} I I\right)+E k_{2} \tau_{2} \cosh _{1}\left(k_{2} H\right)=0$, 
where

$$
\sigma_{n}=(\mu+x) h_{n}{ }^{2}+\mu h^{2}-\psi \tau_{n}, \quad n=1,2 .
$$

The characteristic equation of the system [22] is:

$$
\begin{gathered}
\frac{\operatorname{tgh}\left(\eta_{1} H\right)}{\operatorname{tgh}\left(k_{1} H\right)}-\frac{(2 \mu+x+\lambda) \eta^{2}-k^{2} \lambda}{(2 \mu+x)^{2} \eta k^{2} k_{1}\left(\tau_{2}-\tau_{1}\right)} . \\
\cdot\left|\sigma_{1} \tau_{2}-\sigma_{2} \tau_{1} \frac{k_{1}}{k_{2}} \frac{\operatorname{tgh}\left(k_{2} H\right)}{\operatorname{tgh}\left(h_{1} H\right)}\right|
\end{gathered}
$$

In the limit of the usual elasticity, equation [23] reduces to the perior equation for Iamb waves (5.11). The tlisenssion of the traseendental equation [23] presents great ilficulties and, therefore, only the asymptotic limits for long and short waves are considererl.

For waves long comparest with tle thickness $2 I I$, the protucts $\eta H, k_{1} H, k_{2} H$ are so small that the lyperbolie funetions are replaced by their suguments and equation [23] takes the form:

$$
(2 \mu+*)^{2} \eta^{2} k^{2}\left(\tau_{2}-\tau_{1}\right)=\left[(2 \mu+*+\lambda) \eta^{2}-h^{2} \lambda\right] \cdot\left(\sigma_{1} \tau_{2}-\sigma_{2} \tau_{1}\right)
$$

For very short waves, the quantities $\eta_{7} H, k_{1} H, k_{2} H$ are liuge and the two ratios of hyperbolic tangents, wlich appeas in equation [23] become unity, giving:

$$
\begin{gathered}
{\left[(2 \mu+x+\lambda) \eta^{2}-k^{2} \lambda\right]\left(\sigma_{1} \tau_{2} k_{2}-\sigma_{2} \tau_{1} k_{1}\right)=} \\
=(2 \mu+2)^{2} \eta k^{2} k_{1} k_{2}\left(\tau_{2}-\tau_{1}\right)
\end{gathered}
$$

In the classica] limit both the equations [24] stnd [25] reduce to the corresponding relations fount in the framework of the usual elasticity ( ${ }^{6}$ ). In particular, equation [25] can be recognizer as the characteristic equation for Rayleigh waves in a micropolar elastic half space.

So far we lave discussed the ease of symmetric vibrations. Tuet us now specialize our stuty to the case of antisymunetric vibutions. The component $u_{2}$ of the displacement vector, the components $t_{11}$ and $l_{22}$ of the stress tensor and the component $m_{13}$ of the couple stress 
tenkor are now antisymmetric with respect to the plane $x_{1}=0$. These conclitions lead to:

$$
B=C=E-G=P=0
$$

and the expressions [19] beome:

$$
\begin{aligned}
& \Phi^{*}=A \sinh \left(\eta x_{1}\right) \\
& y^{*}=D \cosh \left(h_{1} x_{1}\right)+F \cosh \left(k_{2} x_{1}\right) \\
& q^{*} *=I \cosh \left(h_{1} x_{1}\right)+Q \cosh \left(k_{2} x_{1}\right)
\end{aligned}
$$

As in a previonsly considered case, by introrlucing these expressions into equations [12], we get:

$$
\begin{aligned}
& L=\tau_{1} D \\
& \theta=\tau_{2} F
\end{aligned}
$$

where $\tau_{1}$ and $\tau_{2}$ have been already definet. Therefore $\psi_{s}{ }^{*}$ ann now be Hitten as:

$$
\varphi_{3}^{*}=\tau_{1} D \cosh \left(k_{1} x_{1}\right)+\tau_{2} F^{\prime} \cosh \left(k_{2} x_{1}\right)
$$

The boundary conditions [1] are now expressed as:

$$
\begin{gathered}
A\left[\eta^{2}(2 \mu+\varkappa+\lambda)-\lambda h^{2}\right] \sinh (\eta H)-D \mathrm{i} k_{k_{1}}(2 \mu+\varkappa) \sinh _{1}\left(k_{1} I I\right)- \\
-H^{2} i k k_{2}(2 \mu+x) \sinh \left(k_{2} H\right)=0,
\end{gathered}
$$

$A i k \eta\left(2 \mu \div\right.$ B) $\cosh (\eta I)+D \sigma_{1} \cosh \left(k_{1} H\right)-F \cdot \sigma_{2} \cosh \left(k_{2} H\right)=0$,

$$
D \tau_{1} k_{1} \sinh \left(k_{1} H\right)+F \tau_{2} k_{2} \sinh \left(k_{2} H\right)=0 \text {. }
$$

The characteristic equation of the system [28] is:

$$
\begin{gathered}
\left(\frac{\sigma_{1} \tau_{2} k_{2}}{\operatorname{tgh}\left(k_{1} H\right)}-\frac{\sigma_{2} \tau_{1} k_{1}}{\operatorname{tgh}\left(k_{2} I\right)}\right) \operatorname{lgh}(\eta H)= \\
=\frac{(2 \mu+x)^{2} k^{2} \eta^{2} k_{1} k_{2}\left(\tau_{2}-\tau_{1}\right)}{(2 \mu+*+\lambda) \eta^{2}-k^{2} \lambda}
\end{gathered}
$$

In the dassical limit equation [29] reduces to the corresponding relation found in the framework of the ustual elasticity (?). 
For waves long comparet with the thickness $2 H$, retaining 11 , to the third terms of the power expansion of the hyperbolic functions, equation [29] becomes:

$$
\begin{gathered}
\left(3-\eta H^{2}\right)\left|\frac{\sigma_{1} \tau_{2}}{k_{1}^{2}\left(3-k_{2^{2}} H^{2}\right)}-\frac{\sigma_{2} \tau_{1}}{k_{2}{ }^{2}\left(3--k_{1}{ }^{2} H^{2}\right)}\right|= \\
=\frac{(2 \mu+\varkappa)^{2}\left(\tau_{2}-\tau_{1}\right)}{(2 \mu+\nu+\lambda) \eta^{2}-k^{2} \lambda}
\end{gathered}
$$

This is the periot equation for long Ilexural waves. Dispersion oecurs for these waves, with phase velocity decreasing to zero with inereasing wave length.

In the elassical limit, equation [30] reduces to the corresponding relation found in the framework of the usual elastieity $\left({ }^{8}\right)$.

For wave lengths small compared to the thickness $2 H$, equation [30] retuces to equation [25].

\section{Love WAVES}

The components of the stress and couple stress tensors determined by the displacement field $\left(0,0, a t_{3}\right)$ and by the microrotation fichl $\left(\varphi_{1}, p_{2}, 0\right)$ are:

$$
\begin{aligned}
& t_{11}=t_{22}=t_{33}=t_{21}-t_{12}=0 \\
& t_{13}=(\mu+\varkappa) u_{3,1}+\varkappa \varphi_{3} \\
& t_{31}=\mu u_{9,1}-\varkappa \varphi_{2} \\
& t_{23}=(\mu+\varkappa) u_{3,2}-\varkappa \varphi_{1} \\
& t_{92}=\mu u_{3,2}+\% \varphi_{1} \\
& m_{11}=(\beta+\gamma) \varphi_{1,1}+\alpha \Theta \\
& m_{22}=(\beta+\gamma) \varphi_{2,2}+\alpha \Theta \\
& m_{33}=\alpha \Theta \\
& m_{12}=\gamma \varphi_{2,1}+\beta \varphi_{1,2} \\
& m_{21}=\gamma \varphi_{1,2}+\beta \varphi_{2,1} \\
& m_{13}=m_{31}=m_{23}=m_{32}=0
\end{aligned}
$$

Let us now assume that a monochromatic wave propagates, along the $x_{2}$-direction, in an infinite mieropolar clastie plate, whose thickness is $2 H$. Morcover we assume that the surfaces of the plate 
are free of stresses ant couple stresses. This leads to the following boundary conditions:

$$
\iota_{13}=m_{11}=m_{12}=0, \text { at } \quad x_{1}= \pm H
$$

Equations [9.1)] are satisfied by:

$$
\begin{aligned}
& \varphi_{1}=A, 1-\Gamma_{, 2} \\
& \varphi_{2}=A, 2+\Gamma_{1}
\end{aligned}
$$

provideal:

$$
\left.\begin{array}{l}
{\left[(\alpha+\beta+\gamma) \nabla^{2}-2 z-I \partial^{2} / \partial t^{2}\right] A=0} \\
{\left[\gamma \nabla^{2}-2 z-I \partial^{2} / \partial t^{2}\right] \Gamma-\approx u_{3}=0} \\
{\left[(\mu-1-x) \nabla^{2}-\partial^{2} / \partial t^{2}\right] u_{3}-1-* \nabla^{2} \Gamma=0}
\end{array}\right\}
$$

The last two equations [33], after simple manipulations, ean be redueed to the following form:

$\left\{\left[\gamma \nabla^{2}-2 x-I \partial^{2} / \partial t^{2}\right]\left[(\mu+x) \nabla^{2}-\varrho \partial^{2} / \partial t^{2}\right]+x \nabla^{2}\right\} \Gamma=0 \quad[34 . a]$ $\left\{\left[\gamma \nabla^{2}-2 *-I \partial^{2} / \partial t^{2}\right]\left[(\mu+x) \nabla^{2}-\rho^{2} \partial \partial t^{2}\right]+* \nabla^{2}\right\} u_{3}=0$

Let us assume solutions of the form:

$$
\begin{aligned}
& A\left(x_{1}, x_{2}, t\right)=\Lambda^{*}\left(m_{1}\right), i\left(i, x_{0}-\omega i\right) \\
& \Gamma\left(x_{1}, x_{2}, t\right)=\Gamma^{*} \quad\left(x_{1}\right) e^{i\left(k x_{2}-\omega t\right)} \\
& u_{3}\left(x_{1}, x_{2}, t\right)=u_{3}^{*}\left(x_{1}\right) e^{i\left(k x_{n}-\omega t\right)}
\end{aligned}
$$

T'len the first equation [33] and equations [34] become:

$$
\begin{gathered}
A^{*}, 11-\left(k^{2}+\frac{x^{2}}{v_{2}^{2}}\right) A^{*}=0 \\
\left\{\left(\frac{d^{2}}{d x_{1}{ }^{2}}-k^{2}+a^{2}\right)\left(\frac{d^{2}}{d x_{1}^{2}}-k^{2}+d^{2}-b^{2}\right)+\sigma^{2}\left(\frac{d^{2}}{d x_{1}{ }^{2}}-k^{2}\right)\right\} \Gamma^{*}=0 \\
\left\{\left(\frac{d^{2}}{d x_{1}{ }^{2}}-k^{2}+a^{2}\right)\left(\frac{d^{2}}{d x_{1}{ }^{2}}-k^{2}+d^{2}-b^{2}\right)+\sigma^{2}\left(\frac{a^{2}}{d x_{1}^{2}}-k^{2}\right)\right\} u_{3}^{*}=0
\end{gathered}
$$


where

$$
v_{2}^{2}-\frac{a+\beta+\gamma}{\frac{2 \varkappa}{\omega^{2}}-I}
$$

We soarel, as in the previous rase, solutious of equations [36] and [3i] ol the form:

$$
\begin{aligned}
A^{* *}= & A \sinh \left(\zeta x_{1}\right)+B \cosh \left(\zeta x_{1}\right) \\
I^{*}= & C \sinh \left(k_{1} x_{1}\right)+D \cosh \left(k_{1} x_{1}\right)+ \\
& +F \sinh \left(k_{2} x_{1}\right)+F^{\top} \cosh \left(h_{2} x_{1}\right) \\
u_{2}^{*}= & G \sinh \left(k_{1} x_{1}\right)+L \cosh \left(h_{1} x_{1}\right) \therefore \\
& +P \sinh \left(k_{2} x_{1}\right)+Q \cosh \left(k_{2} x_{1}\right)
\end{aligned}
$$

wlere

$$
\zeta^{2}=k^{2}-\frac{1}{r_{2}^{2}}
$$

Let us now specialize our study to the case of symmetrie vilhrations. Then the component $\psi_{2}$ of the microrotation vector, the components $m_{11}$ and $m_{22}$ of the eomple stress teusor and the component $t_{13}$ of the stress tensor must he symmetric with respect to the plane $x_{1}-0$. This leads to:

$$
\begin{aligned}
& A=D=F=L=Q=0, \\
& G=\xi_{1} C \\
& I^{3}=\xi_{2} K
\end{aligned}
$$

where:

$$
\xi_{n}=\frac{x\left(h^{2}-h_{n^{2}}\right)}{(\mu+*)\left(h^{2}-\cdot h\right)+\varrho h^{2}}, \quad n=1,2 .
$$

From the assumption that the determiuat of the system of the three homogeneous erpations, obtainel giving nu explicit expression to the boumlary woulitions $[3 \%]$, must be zero, we get the following period equation: 


$$
\begin{aligned}
& \frac{\operatorname{tgh}(\zeta H)}{\operatorname{tgh}\left(k_{1} H\right)}=\left\{(\gamma+\beta) k^{2}\left(g_{2} k_{1} \frac{\operatorname{tgh}\left(k_{2} H\right)}{\operatorname{tgh}\left(k_{1} H\right)}-g_{1} k_{2}\right)+\right. \\
& \left.+\left\lfloor(\alpha+\beta+\gamma) \zeta^{2}-a k^{2}\right]\left(g_{1} f_{2}-g_{2} f_{1} \frac{\operatorname{tgh}\left(k_{2} H\right)}{\operatorname{tgh}\left(k_{1} H\right)}\right)\right\} . \\
& ,\left\{(\gamma+\beta)^{2} k^{2}\left(k_{1} f_{2}-k_{2} f_{1}\right)\right\}-\mathrm{I}
\end{aligned}
$$

where:

$$
\left.\begin{array}{l}
g_{n}=\frac{\hat{\imath}-\beta}{2}\left(k_{n}^{2}+k^{2}\right)+\frac{\gamma-\beta}{2}\left(k_{n}^{2}-k^{2}\right) \\
f_{n}=(\mu+x) k_{n} \xi_{n}+x k_{n}
\end{array}\right\}, n=1,2 .
$$

For wave lengths small rompared to the thickness $2 H$, equation [39] retuces to:

$$
\begin{aligned}
& 2(\gamma+\beta) k^{2} \zeta\left(k_{1} f_{1}-k_{2} f_{2}\right)=\left(g_{2} f_{1}-g_{1} f_{2}\right) \\
& \cdot\left[(\gamma+\beta) \approx k^{2}-(\alpha+\beta+\gamma) \zeta^{2}-\alpha^{2} h^{2}\right]
\end{aligned}
$$

It is obvious that we have no counterpart of equations [39] and [40] in classical elasticity. However we may conclude that in a micropolar elastic medium we have waves of Jove type, while, in the classical framework, this is possible only in a layered medium by imposing some conditions on the material constants.

Let us now specialize ou sturly to the case of antisymmetric vibrations. The component $\varphi_{2}$ of the mierorotation vector, the components $m_{11}$ and $m_{22}$ of the couple stress tensor and the component $t_{13}$ of the stress tensor are antisymmetric with respect to the plane $r_{1}=0$. These conditions lead to:

$$
\begin{aligned}
& B=C=H=Q=P=0 \\
& L=\xi_{1} D \\
& Q=\xi_{2} F
\end{aligned}
$$

and by the procedure, already mployed in the previous cases, we get the following period equation: 


$$
\begin{aligned}
& \left.\frac{\operatorname{tgh}(\zeta H)}{\operatorname{tgh}\left(k_{1} H\right)}=\mid(\gamma+\beta)\left(k_{1} f_{2}-k_{2} f_{1}\right) k^{2} \zeta\right]\left\{\left[(\alpha+\beta-\gamma \cdot \gamma) \zeta^{2}-\alpha k^{2} \mid .\right.\right. \\
& \cdot\left[g_{1} f_{2}-g_{2} f_{1} \frac{\operatorname{tgh}\left(k_{1} I I\right)}{\operatorname{tghh}\left(k_{2} H\right)}+\right. \\
& +\frac{1}{2}(\gamma \div \beta) *^{2} H^{2}\left[k_{1} g_{2} \frac{\operatorname{tgh}\left(k_{1} I I\right)}{\operatorname{tgh}\left(k_{2} I\right)}-k_{2} g_{1} \mid\right\}-1
\end{aligned}
$$

For wave lengths small comparer with the thickness $2 I I$, equation [41] reduces to equation [40].

\section{CONCLTHAONK}

We Jave starlierl the Lamb and Love wave proparation in an infinite Jomogeneous miepopolar elastic plate with free boundary surfaces. We have found that a sisplacement fielsl $\left(u_{1}, u_{2}, 0\right)$ ant a microrotation fielk $\left(0,0, \varphi_{3}\right)$ leasls to waves which ean be consislered of Lamb's kind, while a displacement: field $\left(0,0, u_{3}\right)$ and a microrotation field $\left(\varphi_{1}, \varphi_{2}, 0\right)$ lewls to waves which can be consicleres of Iuve's kind. Therefore it is possible to have, in micropolar mealia, Love waves without the conditions required in the framework of classical elasticity.

\section{ACKNow LEDGLHENTs}

I wish to thank Prof. M. Cuputo for valuable discussions, encouragements and support in this work.

\section{REFERENCES}

(1) Bosenr E., 1972. - Bodly Force and Body Couple Equivalents for Seismic Dislocations in Miompolar Medin, to be published.

(2) Boscin E., 1972. - Body Force, Body Couple and Heat Souree Rquinalents for Seismic Disloentions in Mieropolar Metla, to be publishet.

(3) Eningex A. C., 1966 . - Linear Theory of Mioropolar Elasticily. "J. Math, and Mech." $15,909$. 
(4) Ewixg W. M., Jarpataks W. S., Press F., 1957. - Elastie Wares in Layered Medir. Now Jork.

(5) See, e.g., o 1 . [6-12], patge 283, of Rof. 4.

(5) Sce, e.g, cq. [0-15] ant [6-17], page 283, of Ref. 4.

(7) Sec, e.g., ca. [6-11], page 283, of Rel'. 4.

(B) See, e.g., eq. [6-21], page 285, of Reri. 4.

(9) Gogoladze V. (†., 19+7. - Dispersion of Rayleigh wares in a Layer. Pull. Inst. Scism. Acat. Sci. II.R.S.S., 119, 27.

(10) Insax D., 1969. -- Sur la Theorie de la Thermorlasticils Mieropolaire Couple. "(. Reml. Araul. Sic. Puris", 268, 58.

(11) Lasis II, 1916. - On Ilaves in an Flastic Plate. "Proce. Roy. Soc. (1.om(lon)", 1, 93, 114.

(12) Prescott J., 19+2. - Elnstie Waves and ribrations of Thin Fods. "l'lil. Ing. ", 33. 703.

(13) RAYtxun, 1889. - On the Free Tibretions of an Infinite Ilate of Ho-

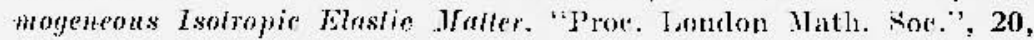
225.

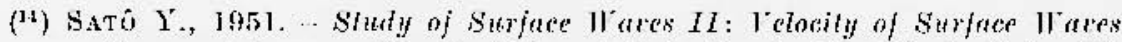
Propagated "tpon Elastic Plates. "Bull. Eattl. TRes. Inst. (Toliqo)", $29,223$. 